\title{
CRESCIMENTO DE FIGUEIRA SOB DIFERENTES CONDIÇÕES DE CULTIVO ${ }^{1}$
}

\author{
Andréa Carvalho da Silva ${ }^{2}$, Sarita Leonel ${ }^{3}$, \\ Adilson Pacheco de Souza ${ }^{2}$, Manoel Euzébio de Souza ${ }^{3}$, Adriana Aki Tanaka ${ }^{3}$
}

\begin{abstract}
FIG TREE GROWTH

UNDER DIFFERENT CROP CONDITIONS

The plant growth analysis can be a good tool to evaluate the yield physiological basis and the influence of environmental, genetic, and agronomic traits. The Ficus carica L. growth, under irrigation and mulch (crushed sugar-cane), was evaluated in Botucatu, São Paulo State, Brazil. The experimental design was randomized blocks, in a $2 \times 2$ factorial scheme (mulch $\mathrm{x}$ irrigation), with 4 replications and each replication consisting of 3 plants, under the following treatments: T1 - without irrigation or mulch; T2 - without irrigation and with mulch; T3 - with irrigation and without mulch; T4 - with irrigation and mulch. Destructive and non-destructive analysis were carried out at $7,55,76,97,114,135,156,176,198,219,240,254$, and 275 days after transplanting, based on the following parameters: branch and stem diameter, branch length, and number of leaves, internodes, and fruits. Different plant organs were partitioned to obtain the fresh and dry mass of isolated partitions. The leaf area $\left(\mathrm{cm}^{2}\right)$ was measured with a photoelectric device and the irrigation management was carried out with the aid of a tensiometer, keeping the soil matric potential close to $-30 \mathrm{kPa}$. The use of mulch and irrigation favored the development of plants (stem diameter of $36.60 \mathrm{~mm}$ and branch length of $1.28 \mathrm{~m}$ ), and the crop growth rate, relative growth rate, and net assimilation rate were respectively $7 \mathrm{~g} \mathrm{~m}^{-2}$ day $^{-1}, 0.015 \mathrm{~g} \mathrm{~g}^{-1}$ day $^{-1}$, and $17 \mathrm{~g} \mathrm{~m}^{-2}$ day $^{-1}$. These rates showed that the mulch provided satisfactory hydric conditions to a fast establishment of seedlings.
\end{abstract}

KEY-WORDS: Ficus carica L.; biomass; irrigation management; mulch.

\section{INTRODUÇÃO}

Do ponto de vista agronômico, a sustentabilidade pode ser alcançada com o uso de práticas conservacionistas que priorizem o aporte de resíduos vegetais, promovendo alterações físicas,

\section{RESUMO}

A análise de crescimento de plantas pode ser considerada um bom indicativo para a avaliação das bases fisiológicas de produção e da influência exercida por variáveis ambientais, genéticas e agronômicas. Avaliou-se o crescimento da figueira 'Roxo de Valinhos', submetida a irrigação e cobertura morta (bagacilho de cana-de-açúcar triturado), em Botucatu (SP). O experimento utilizou blocos casualizados, em esquema fatorial $2 \times 2$ (cobertura morta $\mathrm{x}$ irrigação), com 4 repetições, sendo cada repetição constituída por 3 plantas, com caracterização dos seguintes tratamentos: T1 - sem irrigação e sem cobertura morta; T2 - sem irrigação e com cobertura morta; T3 - com irrigação e sem cobertura morta; T4 - com irrigação e cobertura morta. Foram realizadas análises destrutivas e não destrutivas, aos 7, 55, 76, 97, 114, 135, 156, 176, 198, 219, 240, 254 e 275 dias após o transplantio, com base nos seguintes parâmetros: diâmetro do ramo e do caule, comprimento do ramo, número de folhas, número de entrenós e número de frutos. Foram particionados os diferentes órgãos da planta, para obtenção da massa seca e fresca das partições isoladas. As medições da área foliar $\left(\mathrm{cm}^{2}\right)$ foram realizadas com aparelho integrador fotoelétrico. O manejo da irrigação foi realizado com o auxílio da técnica de tensiometria, mantendo o potencial matricial do solo próximo a $-30 \mathrm{kPa}$. O uso de cobertura morta e irrigação favoreceu o desenvolvimento das plantas (diâmetro do caule de $36,60 \mathrm{~mm}$ e comprimento do ramo de $1,28 \mathrm{~m}$ ), e as taxas de crescimento, crescimento relativo e assimilatória líquida da cultura foram de $7 \mathrm{~g} \mathrm{~m}^{-2} \mathrm{dia}^{-1}, 0,015 \mathrm{~g} \mathrm{~g}^{-1} \mathrm{dia}^{-1}$ e $17 \mathrm{~g} \mathrm{~m}^{-2} \mathrm{dia}^{-1}$, respectivamente. As taxas indicaram que a cobertura morta ofereceu condições hídricas satisfatórias ao rápido estabelecimento das mudas.

PALAVRAS-CHAVE: Ficus carica L.; biomassa; manejo da irrigação; cobertura morta.

químicas e biológicas no solo, as quais repercutem na conservação da fertilidade e na manutenção da dinâmica da água no solo (Neves et al. 2006, Reis et al. 2007, Mercante et al. 2008). Sob este enfoque, novos conceitos de sistemas de produção agrícola, baseados na conservação do solo, diversificação de

1. Trabalho recebido em fev./2011 e aceito para publicação em nov./2011 ( $n^{\circ}$ registro: PAT 13223/ DOI: 10.5216/pat.v41i4.13223).

2. Universidade Federal de Mato Grosso, Instituto de Ciências Agrárias e Ambientais, Sinop, MT, Brasil.

E-mails: acarvalho@ufmt.br, adilsonpacheco@ufmt.br.

3. Universidade Estadual Paulista, Faculdade de Ciências Agronômicas, Botucatu, SP, Brasil.

E-mails: sarinel@fca.unesp.br, m.euzebio@fca.unesp.br, tanak@fca.unesp.br. 
culturas, ciclagem de nutrientes e uso sistemático de adubos orgânicos, dentre outras práticas alternativas, vêm sendo desenvolvidos, na busca por equilibrar a produtividade com a conservação do meio ambiente (Salmi et al. 2006).

A agricultura que faz uso da suplementação hídrica é considerada a atividade com maior consumo de água, dentre os vários usos múltiplos existentes, perfazendo a necessidade da adoção de mecanismos que favoreçam o aumento da eficiência do seu uso, sem que a produtividade das culturas seja afetada. $\mathrm{O}$ uso de coberturas, em conjunto com a irrigação suplementar, vem sendo uma das principais formas de manejo em pomares, utilizando-se espécies vegetais de rápido crescimento, para produção de fitomassa, ou outros materiais, como o plástico preto, tela de redução de luz, serragem, gramas e acículas de pinus, dentre outros.

A proteção do solo com cobertura morta promove incrementos na produção, aumenta a água disponível no solo, fornece nutrientes essenciais às plantas (Cadavid et al. 1998), reduz a perda de água por evaporação, resultando em maior crescimento do sistema radicular, na camada superficial, reduz a flutuação da temperatura na superfície e diminui a incidência de plantas espontâneas (Gill et al. 1996, Resende et al. 2005).

Segundo Souza et al. (2010), a taxa de decomposição de resíduos vegetais determina o tempo de permanência da cobertura morta na superfície do solo, e resíduos de gramíneas e leguminosas apresentam distintas taxas de decomposição, quando submetidas a diferentes lâminas de irrigação, e, por conseguinte, quanto maior for a velocidade de decomposição, maiores serão as taxas de liberação dos nutrientes, diminuindo, entretanto, a proteção do solo.

Normalmente, busca-se o emprego de resíduos vegetais que possam ser produzidos na própria propriedade e/ou que possuam baixo custo de aquisição. Por conseguinte, o bagacilho de cana-de-açúcar (bagaço triturado em dimensões aproximadas de $0,5 \mathrm{~cm}$ ) vem sendo largamente empregado como substrato, na produção de mudas de frutíferas (Grassi Filho et al. 2001, Rosa et al. 2005) e em associação com compostos orgânicos, na produção de hortaliças (Vidigal 2010).

Leonel \& Tecchio (2010) relatam que a cultura da figueira é interessante para o Brasil, pois este é, atualmente, o segundo maior exportador de frutos in natura do mundo, e, devido à possibilidade de a produção brasileira coincidir com a entressafra do mercado mundial, no hemisfério Norte, acrescentam, ainda, que, no Estado de São Paulo, a cultura está concentrada na região de Valinhos-Campinas e que o cultivo caracteriza-se, predominantemente, como uma atividade tipicamente familiar.

Para Belini et al. (2010), o bagaço de cana-de-açúcar apresenta disponibilidade sazonal, no período abril-dezembro, com preço indicado de venda de $\mathrm{R} \$ 10,00$ a $\mathrm{R} \$ 35,00$ por tonelada. Em função do excedente de produção destes resíduos vegetais, em usinas de açúcar e álcool, e do custo efetivo da tonelada, corrobora-se, assim, a sua recomendação como destinação alternativa, em função da proximidade das usinas e do tradicional uso de cobertura vegetal na produção de figos, na região.

Hernandez et al. (1994) e Almeida \& Silveira (1997) demonstraram, em trabalhos realizados com figueira, que tanto o excesso como a falta de água são prejudiciais ao bom desenvolvimento das plantas, e que a produção de figos somente na dependência das chuvas pode resultar em baixas produções, bem como a aplicação de lâminas muito altas de irrigação não aumenta a produtividade.

Os índices determinados na análise de crescimento indicam a capacidade do sistema assimilatório das plantas em sintetizar (fonte) e alocar a matéria orgânica, nos diversos órgãos (drenos) que dependem da fotossíntese, respiração e translocação de fotoassimilados dos sítios de fixação de carbono aos locais de utilização ou armazenamento, onde ocorrem o crescimento e a diferenciação dos órgãos. Portanto, a análise de crescimento expressa as condições morfofisiológicas da planta e quantifica a produção líquida, derivada do processo fotossintético, sendo o resultado do desempenho do sistema assimilatório, durante certo período de tempo. Este desempenho é influenciado por fatores bióticos e abióticos à planta (Larcher 2000, Benincasa 2003).

Com este trabalho, objetivou-se avaliar o crescimento de plantas de figueira 'Roxo de Valinhos', utilizando-se cobertura morta (bagacilho de cana-de-açúcar triturado) e irrigação manejada pelo balanço hídrico do solo.

\section{MATERIAL E MÉTODOS}

O trabalho foi conduzido em área experimental do Departamento de Produção Vegetal da Faculdade de Ciências Agronômicas da Universidade Estadual 
Paulista, Campus Botucatu (SP) $\left(22,85^{\circ} \mathrm{S}, 48,45^{\circ} \mathrm{W}\right.$ e altitude de $786 \mathrm{~m}$ ), de outubro de 2009 a julho de 2010. De acordo com Cepagri (2010), pela classificação de Köeppen, o tipo climático é o Cwa, caracterizado como clima temperado quente (mesotérmico), com chuvas no verão e seca no inverno. Durante o período experimental, também foi verificado este comportamento (Tabela 1), pela redução dos níveis de radiação global, nos meses de dezembro e janeiro, em conjunto, ainda, com o aumento das pressões parciais de vapor d'água (umidade relativa do ar), corroborando as observações realizadas por Codatto et al. (2008) e Escobedo et al. (2011).

$\mathrm{O}$ solo da área experimental foi classificado como Nitossolo Vermelho (Embrapa 2006) e apresentou as seguintes características químicas, para as camadas 0-0,20 m e 0,20-0,40 m, respectivamente: $\mathrm{pH}\left(\mathrm{CaCl}_{2}\right)=6,3$ e 6,4; matéria orgânica $=27 \mathrm{~g} \mathrm{dm}^{-3}$ e $22 \mathrm{~g} \mathrm{dm}^{-3} ; \mathrm{Al}=0 \mathrm{mmol}_{\mathrm{c}} \mathrm{dm}^{-3}$ (nas duas profundidades); $\mathrm{H}+\mathrm{Al}=15 \mathrm{mmol}_{\mathrm{c}} \mathrm{dm}^{-3}$ e $14 \mathrm{mmol}_{\mathrm{c}} \mathrm{dm}^{-3} ; \mathrm{K}=$ $2,8 \mathrm{mmol}_{\mathrm{c}} \mathrm{dm}^{-3} \mathrm{e} 2,6 \mathrm{mmol}_{\mathrm{c}} \mathrm{dm}^{-3} ; \mathrm{Ca}=84 \mathrm{mmol}_{\mathrm{c}} \mathrm{dm}^{-3} \mathrm{e}$ $83 \mathrm{mmol}_{\mathrm{c}}^{\mathrm{c}} \mathrm{dm}^{-3} ; \mathrm{Mg}=20 \mathrm{mmol}_{\mathrm{c}} \mathrm{dm}^{-3} \mathrm{e} 17 \mathrm{mmol}_{\mathrm{c}} \mathrm{dm}^{-3}$; $\mathrm{P}=130 \mathrm{mg} \mathrm{dm}^{-3} \mathrm{e} 114 \mathrm{mg} \mathrm{dm}^{-3} ; \mathrm{S}=1,0 \mathrm{mg} \mathrm{dm}^{-3}$ (nas duas profundidades); $\mathrm{B}=0,39 \mathrm{mg} \mathrm{dm}^{-3} \mathrm{e} 0,36 \mathrm{mg} \mathrm{dm}^{-3}$; $\mathrm{Cu}=3,8 \mathrm{mg} \mathrm{dm}^{-3}$ e $3,7 \mathrm{mg} \mathrm{dm}^{-3} ; \mathrm{Fe}=10 \mathrm{mg} \mathrm{dm}^{-3} \mathrm{e}$ $19 \mathrm{mg} \mathrm{dm}^{-3} ; \mathrm{Mg}=4,6 \mathrm{mg} \mathrm{dm}^{-3}$ e $10,0 \mathrm{mg} \mathrm{dm}^{-3} ; \mathrm{Zn}=$ $4,2 \mathrm{mg} \mathrm{dm}^{-3}$ e $3,0 \mathrm{mg} \mathrm{dm}^{-3}$.

O transplantio das mudas de figueira da cultivar 'Roxo de Valinhos', na área experimental, foi realizado no dia 13 de outubro de 2009. O espaçamento adotado foi o de 3,0 m entre linhas e 2,0 m entre plantas, representando densidade de 1.660 plantas ha ${ }^{-1}$ (Penteado \& Franco 1997). O transplantio foi feito seguindo-se as curvas de nível do terreno, em covas com largura, comprimento e profundidade de $0,40 \mathrm{~m}$ x 0,40 $\mathrm{m}$ x $0,60 \mathrm{~m}$, respectivamente. O solo foi corrigido e adubado conforme resultados de análises de solo prévias, seguindo-se as recomendações técnicas de Campo Dall'Orto et al. (1996), com a aplicação, no plantio, de $0,5 \mathrm{~kg}$ de superfostato simples, $0,2 \mathrm{~kg}$ de cloreto de potássio e duas parcelas (novembro e janeiro) de $0,7 \mathrm{~kg}$ de sulfato de amônio por planta.

$\mathrm{O}$ experimento foi desenvolvido utilizando-se blocos casualizados, em esquema fatorial $2 \times 2$ (cobertura morta $\mathrm{x}$ irrigação), com 4 repetições, sendo cada repetição constituída por 3 plantas, com caracterização dos seguintes tratamentos: T1 - sem irrigação e sem cobertura morta (SISC); T2 - sem irrigação e com cobertura morta (SICC); T3 - com irrigação e sem cobertura morta (CISC); T4 - com irrigação e cobertura morta (CICC). A avaliação da irrigação ocorreu em faixas, para permitir baixo custo na instalação e operação do sistema, com distribuição da cobertura morta casualizada ao longo das faixas.

Os tratamentos fitossanitários foram realizados seguindo-se as recomendações de Penteado \& Franco (1997). O bagacilho de cana-de-açúcar (cobertura morta) foi distribuído na área, em densidade de $16 \mathrm{Mg} \mathrm{ha}^{-1}$, apresentando as seguintes características químicas, em percentuais na matéria seca: $\mathrm{N}=$ $0,42 \% ; \mathrm{P}_{2} \mathrm{O}_{5}=0,12 \% ; \mathrm{K}_{2} \mathrm{O}=0,07 \% ; \mathrm{C}=16,60 \%$; relação $\mathrm{C} / \mathrm{N}=40 / 1 ; \mathrm{pH}=5,10$; e matéria orgânica $=$ $30,00 \%$.

O sistema de irrigação adotado foi o de gotejamento, com o emprego de mangueiras gotejadoras

Tabela 1. Valores médios mensais de temperatura do ar, umidade relativa do ar, radiação global e fotossinteticamente ativa (PAR) e precipitação pluvial (Botucatu, SP, 2010).

\begin{tabular}{|c|c|c|c|c|c|c|c|}
\hline \multirow{2}{*}{ Meses } & \multicolumn{3}{|c|}{ Temperatura do ar $\left({ }^{\circ} \mathrm{C}\right)$} & \multirow{2}{*}{$\begin{array}{c}\text { Umidade relativa do ar } \\
\%\end{array}$} & \multirow{2}{*}{$\begin{array}{r}\text { Radiação global } \\
\mathrm{MJ} \text { m }\end{array}$} & \multirow{2}{*}{$\frac{\text { Radiação PAR }}{{ }^{2} \mathrm{~d}^{-1}}$} & \multirow{2}{*}{$\begin{array}{c}\text { Precipitação pluvial } \\
\mathrm{mm} \\
\end{array}$} \\
\hline & Mínima & Máxima & Média & & & & \\
\hline Out./2009 & 15,14 & 26,76 & 20,94 & 62,92 & 20,66 & 10,10 & 141,80 \\
\hline Nov./2009 & 19,75 & 27,35 & 24,63 & 59,15 & 19,86 & 9,71 & 289,00 \\
\hline Dez./2009 & 19,00 & 26,92 & 22,96 & 63,38 & 18,11 & 8,85 & 331,60 \\
\hline Jan./2010 & 19,52 & 27,54 & 23,53 & 69,65 & 16,06 & 7,85 & 350,45 \\
\hline Fev./2010 & 20,11 & 29,44 & 24,78 & 53,84 & 20,99 & 10,26 & 179,90 \\
\hline Mar./2010 & 18,65 & 28,40 & 23,53 & 57,30 & 19,59 & 9,58 & 134,55 \\
\hline Abr./2010 & 17,10 & 26,36 & 21,73 & 55,57 & 17,01 & 8,32 & 71,70 \\
\hline Mai./2010 & 14,06 & 24,31 & 19,18 & 57,30 & 14,27 & 6,98 & 39,45 \\
\hline Jun./2010 & 12,44 & 25,52 & 17,52 & 38,16 & 15,07 & 7,37 & 22,80 \\
\hline Jul./2010 & 13,73 & 26,27 & 20,00 & 48,16 & 14,47 & 7,08 & 55,25 \\
\hline
\end{tabular}

Fonte: Estação Meteorológica do Departamento de Ciências Ambientais da Faculdade de Ciências Agronômicas da Universidade Estadual Paulista, Botucatu (SP). 
MANARI ${ }^{\circledR}$ de polietileno, com espessura de parede de 250 micra, gotejador labirinto tipo plano, vazão nominal de $1,46 \mathrm{~L} \mathrm{~h}^{-1}$, à pressão de $100 \mathrm{kPa}$, e expoente de descarga $(x)$ igual a 0,461 , sendo a distância entre os gotejadores de $50 \mathrm{~cm}$. Ao longo do experimento, o sistema operou com $80,37 \%, 81,41 \%$ e $74,36 \%$, para os coeficientes de uniformidade de Christiansen (CUC), uniformidade de distribuição de água (CUD) e uniformidade estatística (CUE), conforme Keller \& Karmelli (1975) e Merriam \& Keller (1978).

O manejo da irrigação foi realizado por meio de tensiometria, com permanência do potencial de água próximo a $-30 \mathrm{kPa}$, com o auxílio de baterias com dois tensiômetros de mercúrio, instalados a 0,20 m (decisão) e 0,40 m (controle) de profundidade, para definição da lâmina aplicada. Neste trabalho, foram ajustados os seguintes modelos, descritos por Van Genuchten (1980), para obtenção da curva de retenção, empregando-se a ferramenta de otimização Solver do Excel:

$$
\begin{aligned}
& \theta_{20}=0,169+\frac{0,437}{\left[1+(2,8111 \psi)^{1,363}\right]^{0,2663}} \mathrm{e} \\
& \theta_{40}=0,210+\frac{0,641}{\left[1+(2,7 \psi)^{1,5044}\right]^{0,3353}},
\end{aligned}
$$

em que $\theta_{20}$ e $\theta_{40}$ são as umidades volumétricas (em $\mathrm{cm}^{3} \mathrm{~cm}^{-3}$ ), às profundidades de $0,20 \mathrm{~m}$ e $0,40 \mathrm{~m}$, respectivamente, e $\psi$ o potencial de água no solo $(\mathrm{kPa})$, apresentando coeficientes de determinação $\left(\mathrm{r}^{2}\right)$ de 0,9974 e 0,9930 , para as profundidades de 0-20 cm e 20-40 cm, respectivamente (Reichardt \& Timm 2004).

As irrigações, nos tratamentos com e sem cobertura morta, ocorreram em intervalos variáveis, de acordo com a demanda atmosférica (Figura 1),
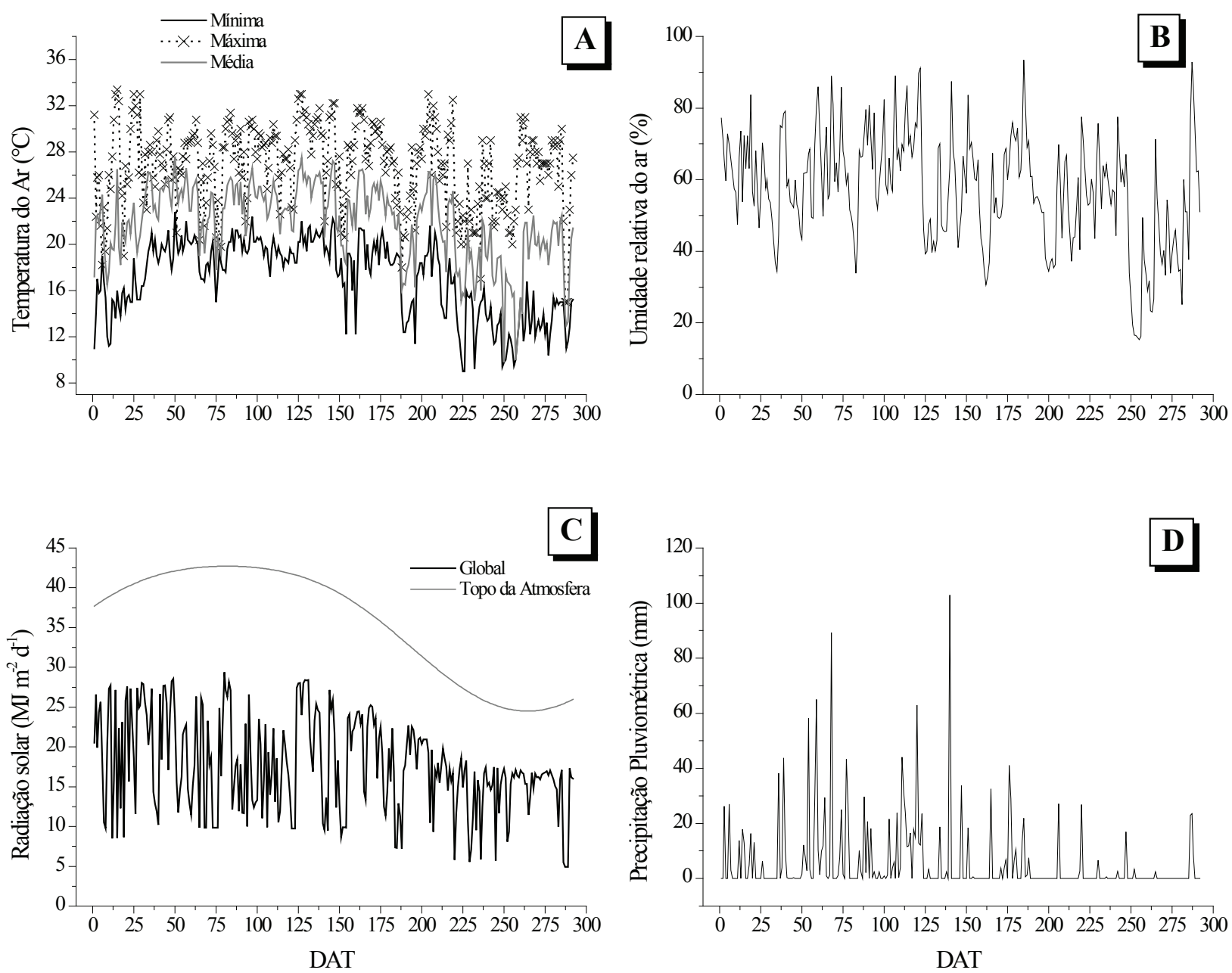

Figura 1. Valores diários da temperatura do $\operatorname{ar}(\mathrm{A})$, umidade relativa do $\operatorname{ar}(\mathrm{B})$, radiação global e no topo da atmosfera (C) e precipitação pluvial (D), em função do número de dias após o transplante (DAT), em 13/10/2009 (Botucatu, SP, 2009). 
principalmente variações das temperaturas e, consequentemente, do déficit de saturação, decorrentes das alterações das pressões de vapor d'água, que, por sua vez, provocaram a elevação da umidade relativa do ar, no verão, a níveis próximos de $16 \%$, entre 252 e 256 dias após o transplante (DAT) (Figura 1B).

Os valores da radiação global, incidentes durante o período experimental (Figura 1C), encontram-se dentro dos intervalos observados por Codatto et al. (2008) e Escobedo et al. (2011). Segundo os mesmos autores, as variações verificadas são decorrentes da diminuição da transmissividade atmosférica, pelas nuvens, no verão, e pela entrada de frentes frias na região, no inverno. Durante o ciclo total, foram aplicados $340,28 \mathrm{~mm}$ e $243,37 \mathrm{~mm}$, com acionamentos do sistema de irrigação por 116,53 e 83,35 horas, para CISC e CICC, respectivamente, perfazendo redução de $28,48 \%$ no volume de água aplicado (Tabela 2). O balanço hídrico representa o somatório das quantidades de água que entram e saem em um volume de solo, à profundidade efetiva ocupada por $80 \%$ do sistema radicular, em determinado intervalo de tempo (Reichardt \& Timm 2004).

A maioria dos trabalhos com irrigação em figueiras abordou o manejo da irrigação em função da evapotranspiração de referência, obtida pelo método do Tanque Classe A (Hernandez et al. 1994, Leonel \& Tecchio 2010), dificultando, assim, comparações, quanto ao volume de água aplicado, visto que esta metodologia não considera o volume de solo explorado pela planta.
Foram utilizadas avaliações não destrutivas e destrutivas, com observação das seguintes características fenológicas de crescimento: diâmetro do ramo e do caule, com o uso de paquímetro digital, comprimento dos ramos, número de folhas, massa fresca e seca. As amostragens ocorreram aos 7, 55, $76,97,114,135,156,176,198,219,240,254$ e 275 dias após o transplantio (DAT), entre outubro de 2009 e julho de 2010, com retirada de uma planta por unidade experimental.

Foram seccionados os diferentes órgãos da planta, para obtenção de massa seca e fresca das partições isoladas (gema apical, folhas, frutos, brotações, parte apical, mediana e basal dos ramos, caule, raiz primária, raiz secundária, raiz terciária e radicelas). A avaliação da área foliar $\left(\mathrm{cm}^{2}\right)$ foi realizada com o auxílio de aparelho integrador fotoelétrico (modelo LI-3000, LICOR). Com base nestas informações e nas metodologias propostas por Silva et al. (2000) e Benincasa (2003), determinaram-se as seguintes taxas de crescimento: taxa de crescimento absoluto do ramo (TCAR, em $\mathrm{cm} \mathrm{dia}{ }^{-1}$ ), taxa de crescimento relativo do ramo (TCRR, em $\mathrm{cm} \mathrm{cm}^{-1} \mathrm{dia}^{-1}$ ); taxa de crescimento absoluto em espessura do diâmetro do ramo (TCAER, em $\mathrm{cm} \mathrm{dia}^{-1}$ ); taxa de crescimento absoluto em espessura caulinar do tronco da planta (TCAEC, em $\mathrm{cm} \mathrm{dia}^{-1}$ ); taxa de crescimento absoluto em fitomassa fresca (TCAFF, em $\mathrm{cm}^{3} \mathrm{dia}^{-1}$ ); Taxa de crescimento relativo em fitomassa fresca (TCRFF, em $\mathrm{cm}^{3} \mathrm{dia}^{-1}$ ); índice de área foliar (IAF, em $\mathrm{m}^{2} \mathrm{~m}^{-2}$ ); taxa de crescimento da cultura (TCC, em $\mathrm{g} \mathrm{m}^{-2} \mathrm{dia}^{-1}$ ); taxa

Tabela 2. Distribuição das precipitações pluviais e lâminas de irrigação (Botucatu, SP, 2009/2010).

\begin{tabular}{cccccccc}
\hline \multirow{2}{*}{ Mês } & $\begin{array}{c}\text { Precipitação } \\
(\mathrm{mm})\end{array}$ & \multicolumn{2}{c}{ Lâmina irrigada $(\mathrm{mm})$} & \multicolumn{4}{c}{ Lâmina efetiva recebida (mm) } \\
\cline { 3 - 8 } & 141,8 & CISC & CICC & SISC & SICC & CISC & CICC \\
\hline Out./2009 & 289,0 & - & - & 141,8 & 141,8 & 141,8 & 141,8 \\
Nov./2009 & 331,6 & - & - & 289,0 & 289,0 & 289,0 & 289,0 \\
Dez./2009 & 350,5 & - & - & 331,6 & 331,6 & 331,6 & 331,6 \\
Jan./2010 & 179,9 & - & - & 350,5 & 350,5 & 350,5 & 350,5 \\
Fev./2010 & 134,6 & 33,29 & 12,86 & 134,6 & 134,6 & 167,9 & 147,4 \\
Mar./2010 & 71,7 & 77,42 & 60,07 & 71,7 & 71,7 & 149,1 & 131,8 \\
Abr./2010 & 39,5 & 86,85 & 75,67 & 39,5 & 39,5 & 126,3 & 115,1 \\
Mai./2010 & 22,8 & 72,74 & 63,29 & 22,8 & 22,8 & 95,5 & 86,1 \\
Jun./2010 & 55,3 & 33,98 & 31,48 & 55,3 & 55,3 & 89,2 & 86,7 \\
Jul./2010 & $1.616,5$ & 304,28 & 243,37 & $1.616,5$ & $1.616,5$ & $1.920,78$ & $1.859,87$ \\
\hline Total & & - & & 179,9 & 179,9 & 179,9 \\
\hline
\end{tabular}

Fonte: Estação Meteorológica do Departamento de Ciências Ambientais da Faculdade de Ciências Agronômicas da Universidade Estadual Paulista, Botucatu (SP). CISC: com irrigação e sem cobertura morta; CICC: com irrigação e cobertura morta; SISC: sem irrigação e sem cobertura morta; SICC: sem irrigação e com cobertura morta. 
de crescimento relativo (TCR, em $\mathrm{g} \mathrm{g}^{-1} \mathrm{dia}^{-1}$ ); e taxa assimilatória líquida (TAL, em $\mathrm{g} \mathrm{m}^{-2} \mathrm{dia}^{-1}$ ).

Quando significativas, as regressões foram ajustadas com o uso do pacote estatístico Sisvar e as representações gráficas realizadas com o programa Origin 6.0. As diferenças entre médias foram submetidas a análise de variância, pelo teste $\mathrm{F}$, e comparadas pelo teste Tukey, a 5\% (Gomes 2009).

\section{RESULTADOS E DISCUSSÃO}

O crescimento das plantas, com o uso da cobertura morta e irrigação, em todas as épocas avaliadas, apresentou os maiores valores, em todas as medidas realizadas, com exceção do número de folhas, que decresceu, a partir de 175 DAT (Figura 2).
Estes resultados enaltecem os benefícios já citados da cobertura morta no crescimento de plantas, pois reduzem a perda de água por evaporação, resultando em maior crescimento do sistema radicular, na camada superficial, e reduzem a flutuação da temperatura, na superfície do solo, como descrito por Carvalho et al. (2001) e Souza et al. (2010).

$\mathrm{O}$ crescimento em diâmetro deve-se, principalmente, à atividade vascular, que é fortemente influenciada por fatores como fotoperíodo, pluviosidade, disponibilidade de nutrientes e espaço físico (Lojan 1968). O uso da cobertura morta propiciou maiores diâmetros de caule e ramos, em todas as épocas avaliadas (Figura 2A). Em CICC, verificaram-se incrementos em torno de $36,60 \mathrm{~mm}$ e $29,71 \mathrm{~mm}$ do caule e do ramo.
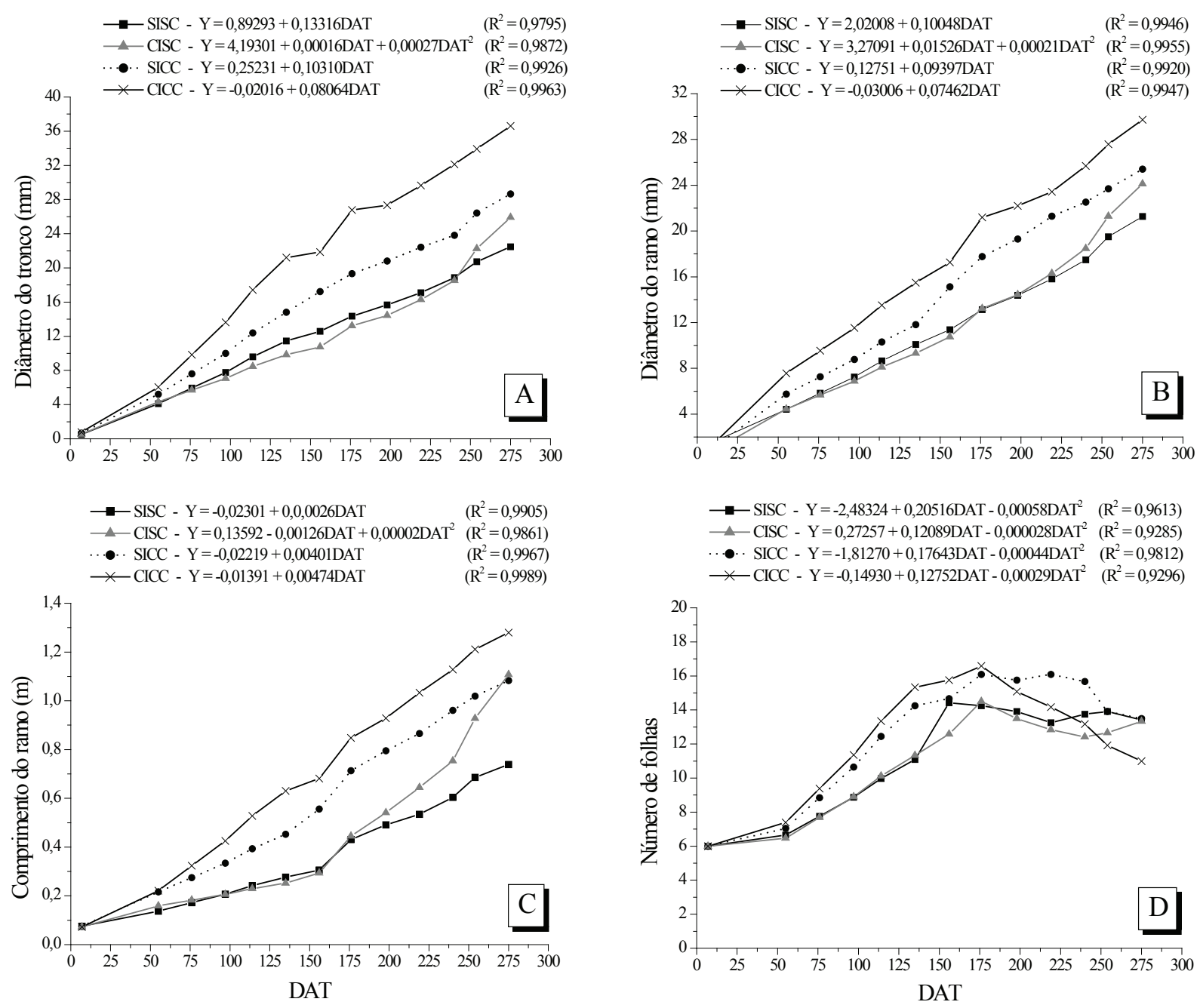

Figura 2. Curvas de crescimento do diâmetro do caule (A) e do ramo (B), comprimento do ramo (C) e número de folhas (D) da figueira 'Roxo de Valinhos', sob as diferentes condições de cultivo (Botucatu, SP, 2010). CISC: com irrigação e sem cobertura morta; CICC: com irrigação e cobertura morta; SISC: sem irrigação e sem cobertura morta; SICC: sem irrigação e com cobertura morta. 
O comprimento do ramo das plantas (Figura 2C) apresentou os maiores valores médios em CICC, chegando, aos 275 DAT, a $1,28 \mathrm{~m}$, valor este superior em $0,54 \mathrm{~m}, 0,08 \mathrm{~m}$ e $0,20 \mathrm{~m}$ a SISC, CISC e SICC, respectivamente. Os resultados encontrados neste trabalho corroboram os apresentados por Leonel \& Tecchio (2010), que verificaram, em ramos primários, comprimentos de $0,96 \mathrm{~m}$ e 1,33 m e diâmetros de $49,01 \mathrm{~mm}$ e $60,32 \mathrm{~mm}$, na safra 2004/2005, para plantas irrigadas e não irrigadas. Já em 2005/2006, estes mesmos autores observaram comprimentos de ramo de $1,04 \mathrm{~m}$ e $1,44 \mathrm{~m}$ e diâmetros de $53,99 \mathrm{~mm}$ e $61,15 \mathrm{~mm}$, nos mesmos sistemas de manejo. Segundo Norberto et al. (2001) e Gonçalves et al. (2006), estas variáveis de crescimento são fundamentais para uma boa produtividade, sendo o seu desenvolvimento influenciado por fatores como época de poda, sistema de condução e umidade do solo, e que podas realizadas no inverno (por volta de 15 de julho), com desponte e umidade satisfatória (irrigação), favorecem os promotores de crescimento, além de elevar a atividade respiratória das plantas.

Os ramos da figueira, assim como os galhos de diversas frutíferas que usualmente formam o dossel aéreo, são órgãos de reserva da planta e podem expressar aumento na produtividade, e os valores encontrados para o diâmetro e comprimento do ramo da figueira evidenciam que fatores como água e cobertura do solo favorecem o crescimento do diâmetro e comprimento dos ramos primários. Já Rufato et al. (2007), avaliando os efeitos de diferentes coberturas vegetais e algumas consorciações entre elas, no desenvolvimento inicial de pessegueiro, encontraram efeito positivo para as variáveis diâmetro de tronco e volume de copa e reduções significativas no comprimento dos ramos $(21 \%$, em relação à testemunha).

$\mathrm{O}$ número de folhas das plantas, em todos os tratamentos, foi crescente até os 175 DAT, todavia, após este momento, houve queda no número de folhas, em decorrência da antecipação das fases fenológicas deste tratamento. Em CICC e SICC, verificaram-se, aos 275 DAT, 45 e 41 entrenós, respectivamente, evidenciando a extrema relação do fator água com a expansão celular e crescimento dos órgãos vegetais. Nicotra \& Davidson (2010) enalteceram a intrínseca relação entre a área foliar vegetal e a condutância estomática, ou seja, em altos e baixos regimes hídricos ocorrem maiores e menores fechamentos estomáticos, em função dos níveis de assimilação de $\mathrm{CO}_{2}$, bem como do acúmulo da biomassa.
Com exceção de CISC, observou-se comportamento linear para os dados primários de diâmetro do caule, diâmetro do ramo e comprimento do ramo. Para o número de folhas (NF), as equações quadráticas possibilitaram valores máximos de 15,66; 13,32; 15,87; e 13,87 , verificados aos 177, 216, 201 e 220 DAT, para SISC, SICC, CISC e CICC, respectivamente.

As taxas de crescimento absoluto do ramo retratam, de maneira acumulativa, a evolução do seu comprimento (Figura 3A). Em CISC, observaram-se as maiores taxas iniciais de crescimento absoluto $\left(1,3 \mathrm{~cm} \mathrm{dia}^{-1}\right)$, enquanto CICC apresentou elevações de TCAR, a partir de 170 DAT $\left(1,0 \mathrm{~cm} \mathrm{dia}^{-1}\right)$, e incremento de $0,35 \mathrm{~cm} \mathrm{dia}^{-1}$, aos 275 DAT. A cobertura vegetal permitiu um rápido estabelecimento da muda, pois os ramos, na sua presença, apresentaram as maiores taxas aos 50 DAT.

A taxa de crescimento de plantas é geneticamente controlada e os fatores que determinam diferentes taxas iniciais de crescimento terão efeito apenas durante a fase de crescimento exponencial das plantas, diminuindo de intensidade à medida em que as plantas se desenvolvem (Carvalho \& Nakagawa 2000). Por conseguinte, as taxas de crescimento relativas do ramo (TCRR) indicam decréscimo na taxa de crescimento, com a evolução temporal das avaliações, para todos os tratamentos (Figura 3B), pois a análise relativa depende dos valores acumulados anteriormente. Com o desenvolvimento de folhas e raízes, os níveis de TCRC decaem de $0,023 \mathrm{~cm} \mathrm{~cm}^{-1} \mathrm{dia}^{-1}$ (5 DAT) para $0,005 \mathrm{~cm} \mathrm{~cm}^{-1} \mathrm{dia}^{-1}$, em CICC, no qual observou-se queda mais acentuada do crescimento relativo do ramo. As maiores taxas de crescimento relativo do diâmetro do ramo também foram observados em CISC.

Os valores das taxas de crescimento absoluto em espessura caulinar TCAEC (Figura 3C) indicam que a ausência de cobertura morta possibilitou os menores incrementos, após o transplantio, corroborando as observações de Resende et al. (2005). Quanto à espessura do ramo, semelhantemente ao diâmetro do caule, a suplementação com água e o uso da cobertura morta permitiram maiores incrementos, com picos máximos ocorrendo aos $175 \mathrm{DAT}$, decorrentes, principalmente, das precipitações ocorridas neste período (Figura 1).

A observação dos valores da fitomassa fresca fornece uma estimativa do aumento de tamanho do fitossistema como um todo, e foi constatado que o acúmulo, na forma de material fresco, foi semelhante 

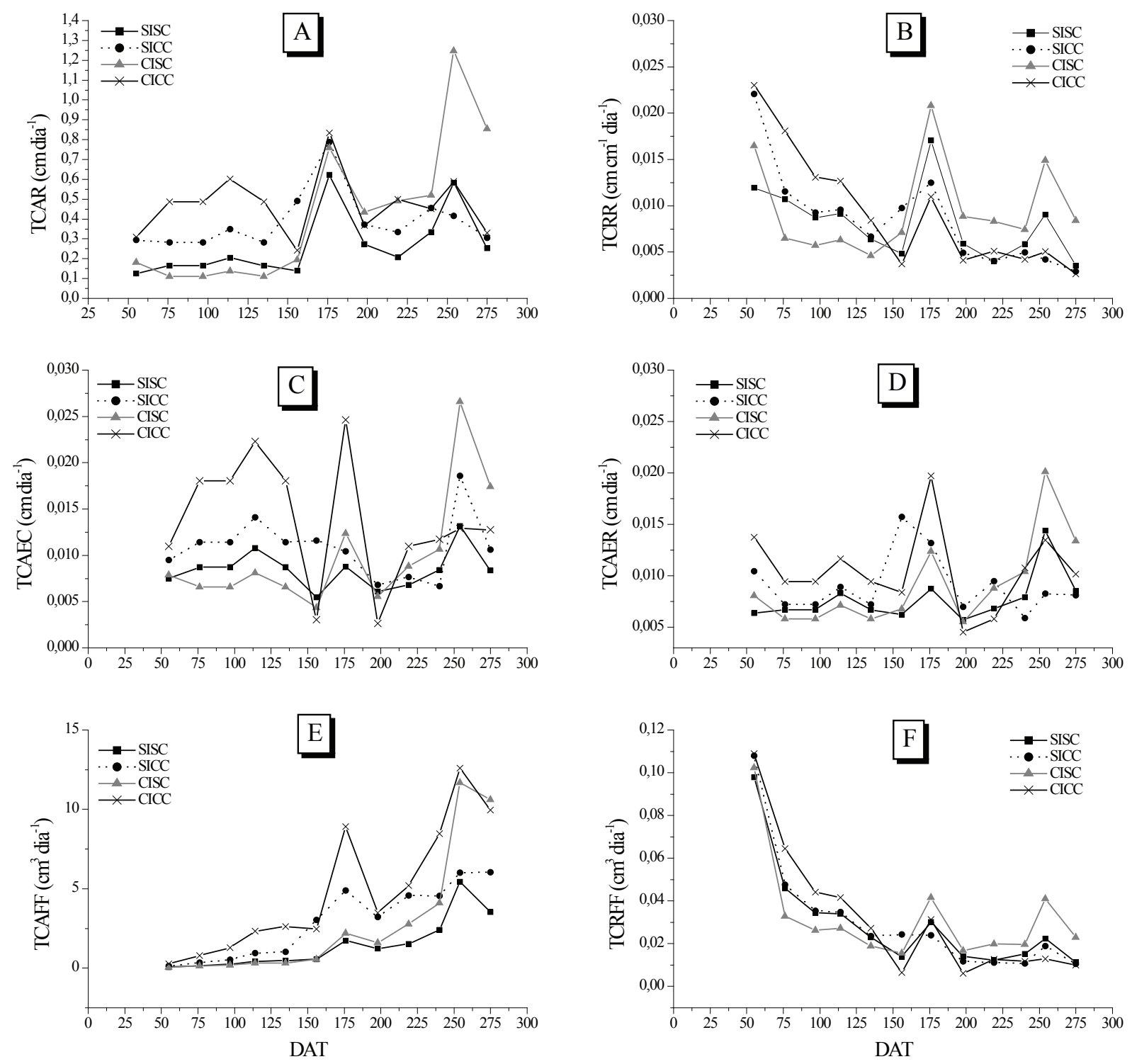

Figura 3. Taxas de crescimento absoluto (A) e relativa do ramo (B), crescimento absoluto em espessura caulinar do tronco da planta (C), crescimento absoluto em espessura do ramo da planta (D), crescimento absoluto da fitomassa fresca (E) e crescimento relativo da fitomassa fresca (F) da figueira 'Roxo de Valinhos', sob as diferentes condições de cultivo (Botucatu, SP, 2010). CISC: com irrigação e sem cobertura morta; CICC: com irrigação e cobertura morta; SISC: sem irrigação e sem cobertura morta; SICC: sem irrigação e com cobertura morta.

entre todos os tratamentos, até 150 DAT. A partir deste momento, CICC e SISC apresentaram os maiores e menores acúmulos de matéria fresca do fitossistema, até 275 DAT, com diferença de, aproximadamente, $10 \mathrm{~cm}^{3} \mathrm{dia}^{-1}$ entre si. De maneira relativa, o acúmulo de fitomassa fresca foi decrescente, com a evolução do ciclo biológico da planta (Figura 3F), com valores iniciais entre $0,11 \mathrm{~cm}^{3} \mathrm{dia}^{-1}$ e $0,10 \mathrm{~cm}^{3} \mathrm{dia}^{-1}$, para todos os tratamentos, aos 5 DAT, e de $0,01 \mathrm{~cm}^{3} \mathrm{dia}^{-1}$ (SISC, SICC e CICC) e $0,02 \mathrm{~cm}^{3} \mathrm{dia}^{-1}$ (CISC), aos 275 DAT.
O índice de área foliar (IAF) é um importante parâmetro biométrico para avaliar respostas de plantas a diferentes condições de ambiente. Observou-se que os menores valores de IAF foram obtidos na ausência de cobertura morta (Figura 4), com picos máximos ocorrendo aos 218 DAT e 227 DAT $\left(0,1043 \mathrm{~m}^{2} \mathrm{~m}^{-2}\right.$ e $\left.0,1094 \mathrm{~m}^{2} \mathrm{~m}^{-2}\right)$, para CISC e SISC, respectivamente, retardando o crescimento da planta e a entrada na fenofase reprodutiva, quando comparados à presença de irrigação, com máximos valores de IAF aos 185 DAT e 206 DAT (CICC e SICC). 

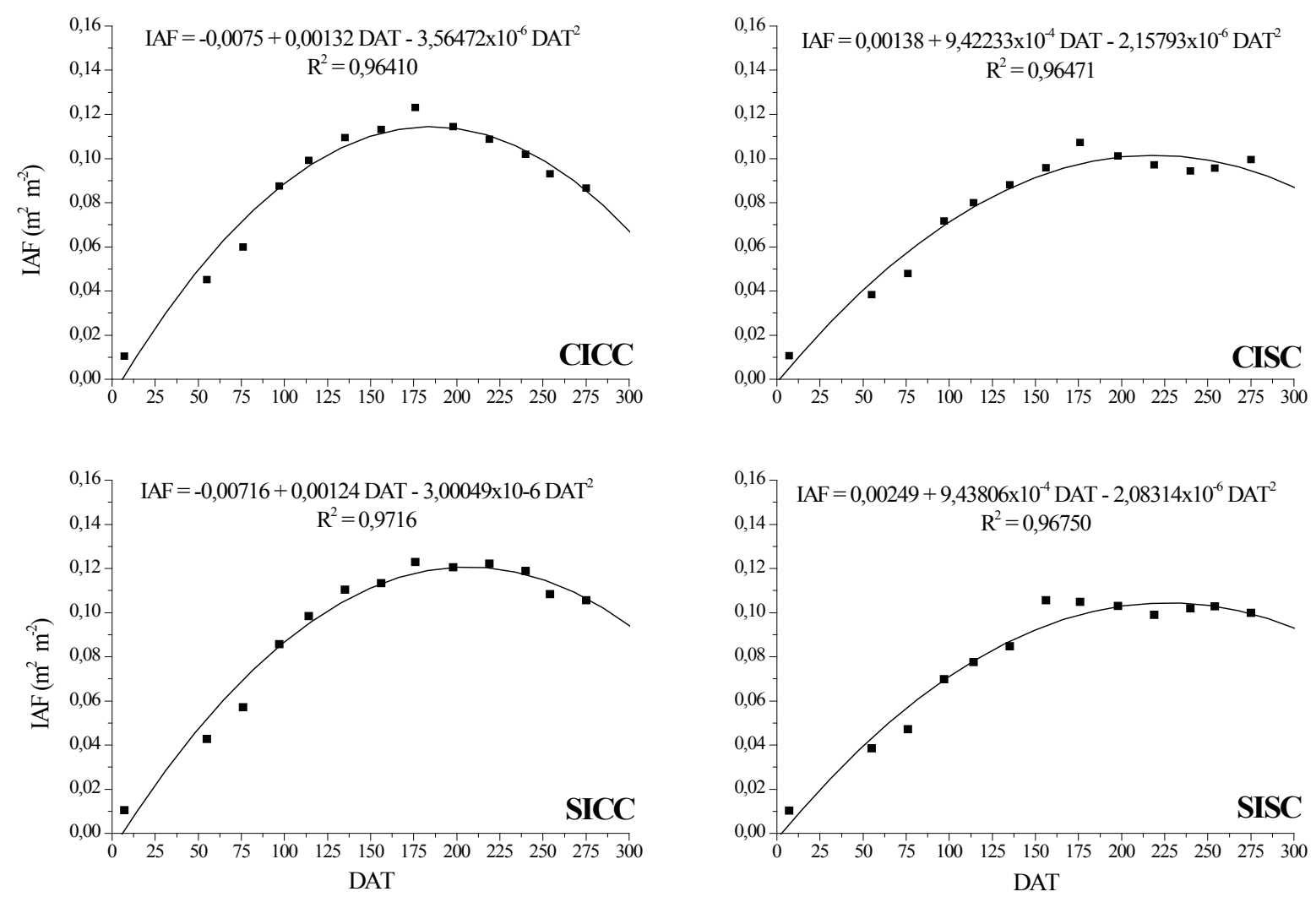

Figura 4. Estimativas do índice de área foliar da figueira 'Roxo de Valinhos', em função do tempo após o transplante, sob as diferentes condições de cultivo (Botucatu, SP, 2010). CISC: com irrigação e sem cobertura morta; CICC: com irrigação e cobertura morta; SISC: sem irrigação e sem cobertura morta; SICC: sem irrigação e com cobertura morta.

$\mathrm{Na}$ ausência de água, os estômatos permanecem fechados por maior tempo, não ocorrendo a entrada do $\mathrm{CO}_{2}$, o que diminui, consequentemente, a transformação do mesmo em carboidratos e o acúmulo de matéria seca.

A presença de cobertura morta e a suplementação hídrica possibilitaram diferenças significativas apenas na massa seca (em percentual) do sistema radicular (Tabela 3). No tratamento CICC, a ordem de acúmulo de matéria seca foi decrescente, nos seguintes órgãos: ramos $\left(275 \mathrm{~g}_{\text {planta }}{ }^{-1}\right)$, folhas
(135 $\left.\mathrm{g} \mathrm{planta}^{-1}\right)$, caule (90 $\left.\mathrm{g} \mathrm{planta}^{-1}\right)$ e sistema radicular $\left(75 \mathrm{~g} \mathrm{planta}^{-1}\right)$. As diferenças observadas dependem da alocação de biomassa, que, por sua vez, é dependente de fatores como espécie, ontogenia e ambiente experimental (Poorter \& Nagel 2000).

As plantas que compuseram o tratamento CISC apresentaram totais de massa seca menores que os do tratamento CICC, com diferença de $120 \mathrm{~g} \mathrm{planta}^{-1}$ entre o órgão de maior e menor acúmulo e similaridade no acúmulo de matéria seca no caule e sistema radicular, ao longo do ciclo. A

Tabela 3. Percentual de massa seca em diferentes partições da figueira 'Roxo de Valinhos', aos 275 DAT, sob as diferentes condições de cultivo (Botucatu, SP, 2010).

\begin{tabular}{lllllr}
\hline Sistema de cultivo & Folhas & Ramos & Caule & Raízes & Frutos \\
\hline SISC & $18,83 \mathrm{~b}$ & $37,83 \mathrm{a}$ & $19,83 \mathrm{a}$ & $22,38 \mathrm{ab}$ & $1,13 \mathrm{a}$ \\
SICC & $19,99 \mathrm{~b}$ & $37,67 \mathrm{a}$ & $16,67 \mathrm{a}$ & $24,17 \mathrm{ab}$ & $1,50 \mathrm{a}$ \\
CISC & $24,17 \mathrm{ab}$ & $34,17 \mathrm{a}$ & $15,67 \mathrm{a}$ & $24,83 \mathrm{a}$ & $1,16 \mathrm{a}$ \\
CICC & $28,50 \mathrm{a}$ & $36,67 \mathrm{a}$ & $15,33 \mathrm{a}$ & $17,83 \mathrm{~b}$ & $1,67 \mathrm{a}$ \\
\hline Médias & 22,87 & 36,59 & 16,88 & 22,30 & 1,37 \\
\hline CV $(\%)$ & 20,91 & 12,83 & 16,20 & 17,83 & 11,82 \\
\hline
\end{tabular}

Médias seguidas da mesma letra, na coluna, não diferem pelo teste Tukey, a 5\%. CISC: com irrigação e sem cobertura morta; CICC: com irrigação e cobertura morta; SISC: sem irrigação e sem cobertura morta; SICC: sem irrigação e com cobertura morta. 
diferença de massa seca entre os ramos e as folhas, em SICC, foi de $75 \mathrm{~g}_{\text {planta }}{ }^{-1}$, com maior expressão a partir dos 100 DAT, enquanto, em SISC, foram verificados os menores valores médios de massa seca, em ordem decrescente como se segue: ramo $\left(120,0\right.$ g planta $\left.^{-1}\right)$, caule $\left(75,0\right.$ g planta $\left.^{-1}\right)$, sistema radicular $\left(60,0\right.$ g planta $\left.^{-1}\right)$ e folhas $\left(45,0\right.$ g planta $\left.^{-1}\right)$.

Leonel \& Damatto Júnior (2007), avaliando a distribuição do sistema radicular da figueira 'Roxo de Valinhos', em função da aplicação de níveis de adubação orgânica, encontraram, no tratamento testemunha, no qual não houve aplicação de nitrogênio na forma de esterco de curral, curtido durante quatro anos, a menor massa total de raízes $(43,3 \mathrm{~g})$, enquanto, com $150 \%$ da dose recomendada, foi observada a maior massa total de raízes (177,7 g). O acúmulo de massa seca do sistema radicular da figueira, nas diferentes condições de cultivo, variou de $60 \mathrm{~g}_{\text {planta }}{ }^{-1}$ a $105 \mathrm{~g} \mathrm{planta}^{-1}$, corroborando os resultados encontrados pelos autores supracitados.
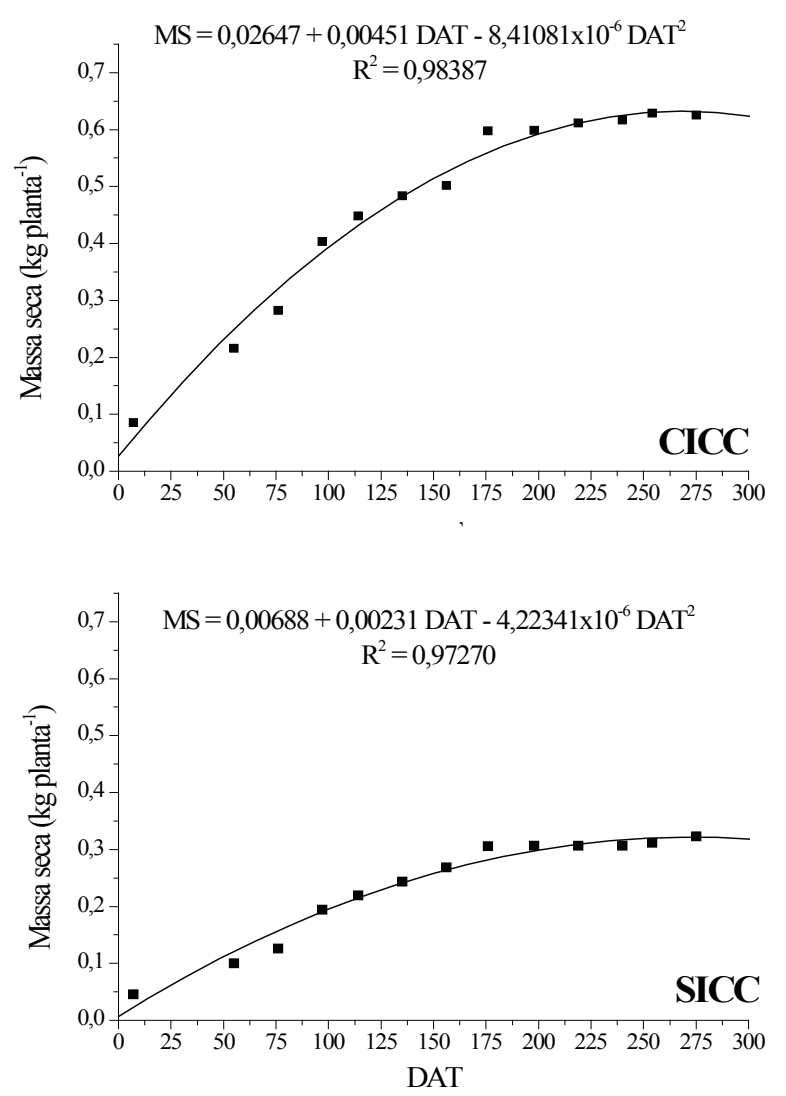

Na Figura 5, estão apresentadas as evoluções da massa seca (MS) da figueira 'Roxo de Valinhos', sob diferentes condições de cultivo, por meio de equações quadráticas decrescentes, em função da senescência das folhas. No tratamento CICC, obteve-se, experimentalmente, no primeiro ciclo de desenvolvimento da planta, massa seca máxima de $0,6 \mathrm{~kg}_{\text {planta }}{ }^{-1}$, aos 250 DAT, com acúmulo crescente dos 50 DAT até os 200 DAT. Todavia, as equações de estimativa possibilitaram, aos 268, 248, 274 e 260 DAT, obter os valores máximos de $0,6311 \mathrm{~kg}$ planta $^{-1}, 0,4617 \mathrm{~kg}$ planta $^{-1}$, 0,3227 kg planta ${ }^{-1}$ e $0,3045 \mathrm{~kg}$ planta $^{-1}$, para CICC, CISC, SICC e SISC, respectivamente. Ocorreu diminuição nas taxas de aumento de massa seca, a partir de 175 DAT, devido à diminuição da expansão foliar e início da fase reprodutiva, todavia, as equações obtidas possibilitaram a obtenção, aos 268, 248, 274 e 260 DAT, de valores máximos de MS iguais a $0,63 \mathrm{~kg}_{\text {planta }}{ }^{-1}, 0,46 \mathrm{~kg}_{\text {planta }}{ }^{-1}, 0,32 \mathrm{~kg}_{\text {planta }}{ }^{-1}$ e $0,30 \mathrm{~kg}$ planta $^{-1}$, para CICC, CISC, SICC e SISC, respectivamente.
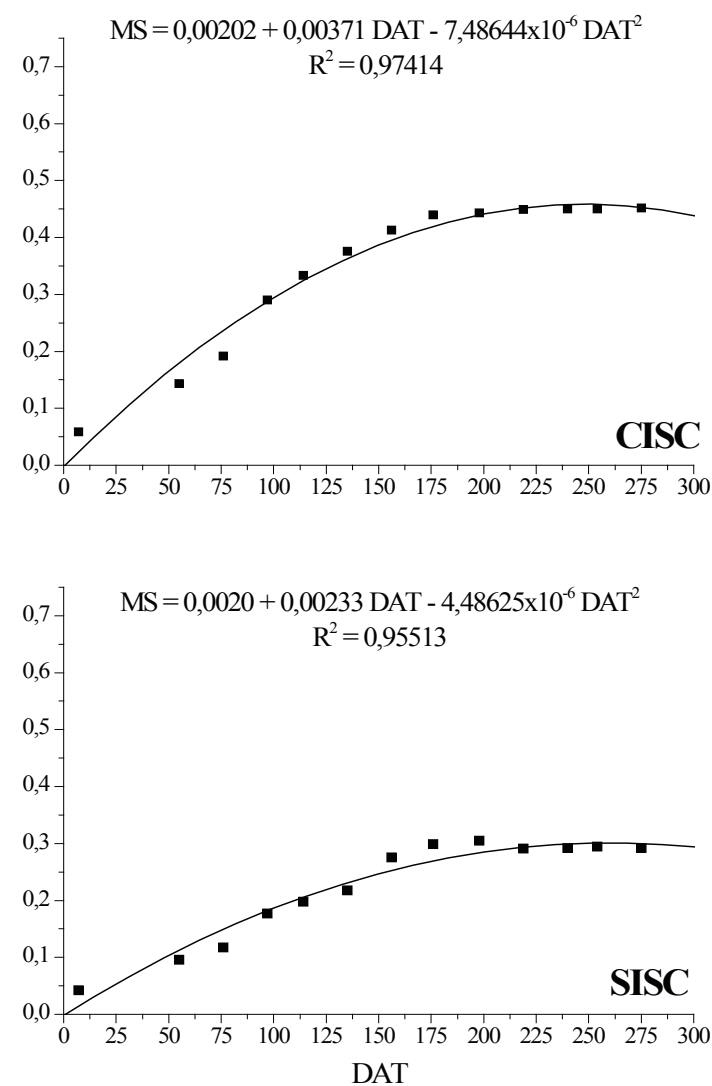

Figura 5. Estimativas de massa seca da figueira 'Roxo de Valinhos', em função do tempo após o transplante, para as diferentes condições de cultivo (Botucatu, SP, 2010). CISC: com irrigação e sem cobertura morta; CICC: com irrigação e cobertura morta; SISC: sem irrigação e sem cobertura morta; SICC: sem irrigação e com cobertura morta. 
A taxa de crescimento da cultura (TCC) representa a produção da biomassa e, pelos polinômios ajustados, evidenciaram-se dois picos de crescimento em CICC (entre 75 DAT e 125 DAT e após 250 DAT), decorrentes da variação da precipitação pluviométrica e da radiação fotossinteticamente ativa (PAR) elevadas (Tabela 1), na fase de estabelecimento da muda e no segundo momento, pelo término da fase reprodutiva, antes de 275 DAT (Figura 6).

A suplementação hídrica beneficiou o início do desenvolvimento, contudo, observou-se decréscimo no acúmulo da biomassa, por estas plantas, entre 75 DAT e 100 DAT, de 3,0 $\mathrm{g} \mathrm{m}^{-2}$ dia $^{-1}$ para 2,0 $\mathrm{g} \mathrm{m}^{-2} \mathrm{dia}^{-1}$. As plantas submetidas a SICC e
SICC apresentaram TCC com valores máximos de 1,5-2,0 $\mathrm{g} \mathrm{m}^{-2} \mathrm{dia}^{-1}$. A taxa de crescimento relativo (TCR) fornece o índice fisiológico mais proveitoso e ecologicamente significante, como medida da eficiência de produção da nova matéria seca sobre a já existente.

Todos os tratamentos apresentaram os maiores índices de crescimento relativo entre 75 DAT e 125 DAT, sendo que a ausência de irrigação propiciou uma dissociação desta taxa, em algumas avaliações, principalmente aos 150 DAT, com maiores níveis de TCC ocasionados pelos maiores níveis de precipitação pluviométrica (Figura 1D). De maneira geral, a diminuição do déficit de pressão de vapor d'água
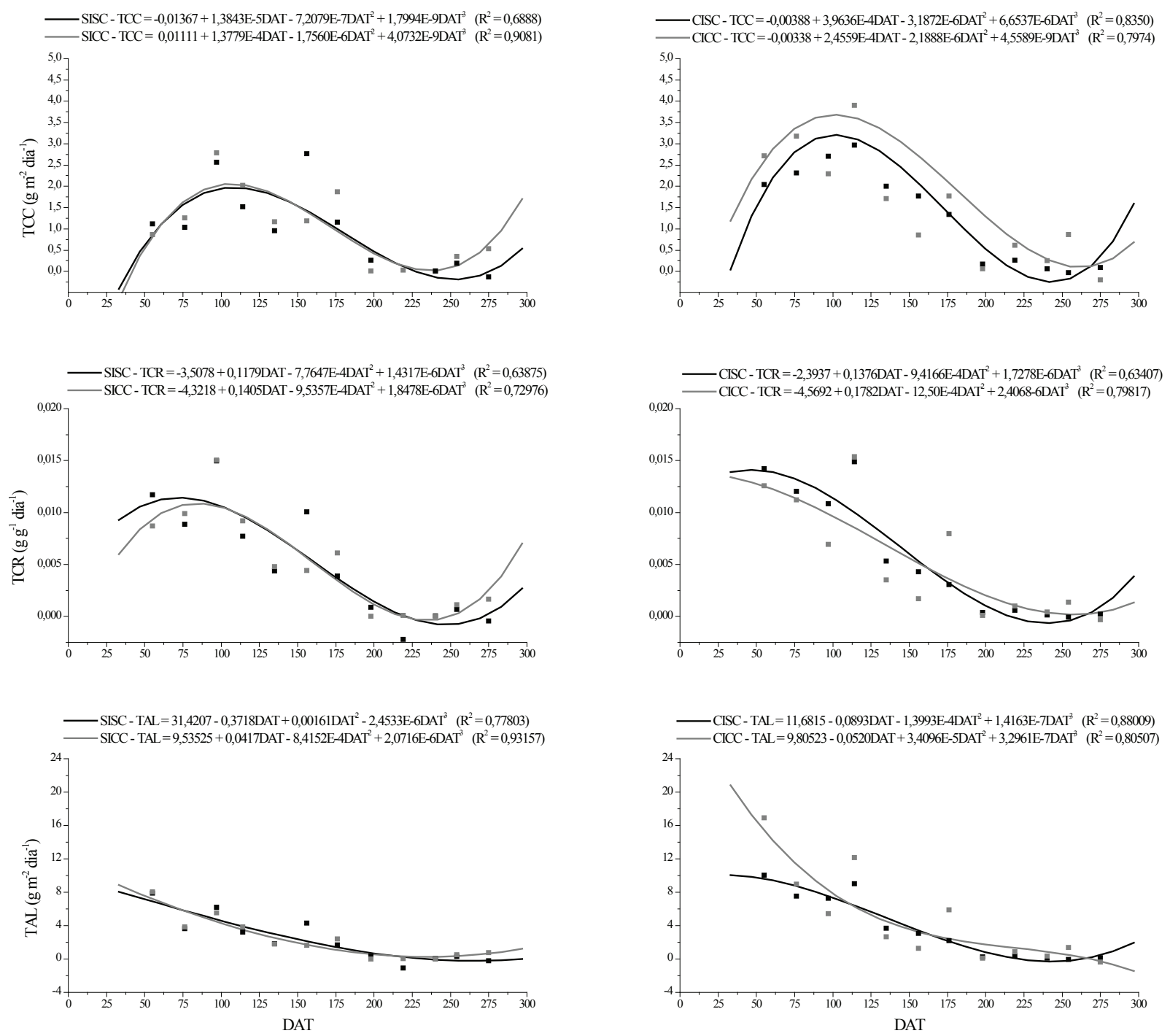

Figura 6. Taxas de crescimento da cultura (TCC), crescimento relativo (TCR) e assimilação líquida (TAL) da figueira 'Roxo de Valinhos', sob as diferentes condições de cultivo (Botucatu, SP, 2010). CISC: com irrigação e sem cobertura morta; CICC: com irrigação e cobertura morta; SISC: sem irrigação e sem cobertura morta; SICC: sem irrigação e com cobertura morta. 
aumenta o crescimento das plantas (como observado nos períodos de maior precipitação), devido a mudanças fisiológicas, como redução na transpiração e aumento da abertura estomática, incrementando a fotossíntese e a eficiência do uso de água (Barradas et al. 2005, Cunningham 2006, Chavarria et al. 2008).

A redução na taxa de crescimento relativo da fitomassa fresca ocorrida neste experimento, entre 75 DAT e 100 DAT, evidencia uma realocação das reservas de carbono, que, até então, eram usadas estruturalmente, na constituição de novas folhas e crescimento da massa do ramo. Rodrigues et al. (2009), avaliando seleções mutantes de figueiras cv. 'Roxo de Valinhos', destacaram a ocorrência de redução na TCR, entre 70 DAT e 80 DAT, devido ao início da frutificação e desenvolvimento dos frutos. As maiores incorporações de $\mathrm{CO}_{2}$, pelas folhas das plantas da figueira 'Roxo de Valinhos', aconteceram na estação de crescimento da planta, com a emissão de novas folhas, no início do desenvolvimento, entre 50 DAT e 125 DAT. Para TCR, os polinômios permitem verificar valores máximos oscilando entre $1,97 \mathrm{~g} \mathrm{~m}^{-2} \mathrm{dia}^{-1}$ e 3,68 $\mathrm{g} \mathrm{m}^{-2} \mathrm{dia}^{-1}$, aos 109 DAT e 101 DAT, para CICC e SISC, respectivamente, e com comportamento semelhante para as demais taxas, todavia, em períodos diferentes do ciclo da planta.

\section{CONCLUSÕES}

1. O uso de cobertura morta diminuiu o consumo de água da planta em $60 \mathrm{~mm}$ e, em conjunto com a suplementação hídrica, favoreceu o incremento das taxas de crescimento, no estabelecimento inicial da lavoura de figueira, e a antecipação da fase reprodutiva.

2. A suplementação hídrica propiciou maiores massas secas do sistema radicular e índice de área foliar, podendo ser um indicativo de maiores produtividades.

\section{REFERÊNCIAS}

ALMEIDA, M. M.; SILVEIRA, E. T. Tratos culturais na cultura da figueira no sudoeste de Minas Gerais. Informe Agropecuário, Belo Horizonte, v. 18, n. 188, p. 27-33, 1997.

BARRADAS, V. L. et al. Transpiration and canopy conductance in young apricot (Prunus armenica L.) trees subjected to different PAR levels and water stress.
Agricultural Water Management, Amsterdam, v. 77, n. 1-3, p. 323-333, 2005.

BELINI, U. L. et al. Aspectos anatômicos e tecnológicos de painéis confeccionados com fibras de eucalipto e canade-açúcar. Cerne, Lavras, v. 16, supl., p. 48-52, 2010.

BENINCASA, M. M. P. Análise de crescimento de plantas: noções básicas. 2. ed. Jaboticabal: Funep, 2003.

CADAVID, L. F. et al. Long-term effects of mulch, fertilization and tillage on cassava grown in sandy soils in northern Colombia. Field Crops Research, Amsterdan, v. 57, n. 1, p. 45-56, 1998.

CAMPO DALL'ORTO, F. A. et al. Frutas de clima temperado: II. Figo, maçã, marmelo, pêra e pêssego em pomar compacto. In: RAIJ, B. V. et al. (Eds.). Recomendações de adubação e calagem para o Estado de São Paulo. 2. ed. Campinas: IAC, 1996. p. 139-140.

CARVALHO, N. M.; NAKAGAWA, J. Sementes: ciência, tecnologia e produção. 4. ed. Jaboticabal: Funep, 2000.

CARVALHO, J. E. B. et al. Manejo de cobertura do solo e desenvolvimento do sistema radicular da combinação laranja 'pêra'/ limão 'cravo' na Bahia e em Sergipe. Laranja, Cordeirópolis, v. 22, n. 1, p. 259-269, 2001.

CENTRO DE PESQUISAS METEOROLÓGICAS E CLIMÁTICAS APLICADAS À AGRICULTURA (Cepagri). Clima dos municípios paulistas. 2010. Disponível em: <http://www.cpa.unicamp.br>. Acesso em: 30 nov. 2010.

CHAVARRIA, G. et al. Relações hídricas e trocas gasosas em vinhedo sob cobertura plástica. Revista Brasileira de Fruticultura, Jaboticabal, v. 30, n. 4, p. 1022-1029, 2008.

CODATTO, G. et al. Global and diffuse solar irradiances in urban and rural areas in southeast Brazil. Theoretical and Applied Climatology, Hamburg, v. 93, n. 1, p. 57-73, 2008.

CUNNINGHAM, S. C. Effects of vapour pressure deficit on growth of temperate and tropical evergreen rainforest of Australia. Acta Oecologica, Paris, v. 30, n. 2, p. 399406, 2006.

EMPRESA BRASILEIRA DE PESQUISA AGROPECUÁRIA (Embrapa). Centro Nacional de Pesquisas em Solos. Sistema brasileiro de classificação de solos. Brasília: Embrapa-SPI; Rio de Janeiro: Embrapa Solos, 2006.

ESCOBEDO, J. F. et al. Ratios of UV, PAR and NIR components to global solar radiation measured at Botucatu site in Brazil. Renewable Energy, Brighton, v. 36, n. 2, p. 169-178, 2011.

GILL, K. S. et al. Tillage, mulch, and irrigation effects on corn (Zea mays L.) in relation to evaporative demand. Soil Tillage Research, Amsterdam, v. 39, n. 3-4, p. $213-$ 227, 1996. 
GOMES, F. P. Curso de estatística experimental. 15. ed. Piracicaba: Fealq, 2009.

GONÇALVES, C.A. A. et al. Poda e sistemas de condução na produção de figos verdes. Pesquisa Agropecuária Brasileira, Brasília, DF, v. 41, n. 6, p. 955-961, 2006.

GRASSI FILHO, H. G. et al. Efeito de diferentes substratos no crescimento de mudas de limoeiro 'Cravo' até o ponto de enxertia. Laranja, Cordeirópolis, v. 22, n. 1, p. 157-166, 2001.

HERNANDEZ, F. B. T.; SUZUKI, M. A.; CORRÊA, L. S. Resposta da figueira (Ficus carica L.) ao uso da irrigação e nitrogênio na região de Ilha Solteira. Scientia Agricola, Piracicaba, v. 51, n. 1, p. 99-104, 1994.

KELLER, J.; KARMELI, D. Trickle irrigation design parameters. Transactions of the ASAE, St. Joseph, v. 17, n. 4, p. 678-684, 1975.

LARCHER, W. Ecofisiologia vegetal. São Carlos: Rima, 2000.

LEONEL, S.; DAMATTO JÚNIOR, E. R. Perfil radicular da figueira sob efeito de níveis de adubação orgânica. Revista Brasileira de Fruticultura, Jaboticabal, v. 29, n. 1, p. 191-194, 2007.

LEONEL, S.; TECCHIO, M. A. Épocas de poda e uso da irrigação em figueira 'Roxo de Valinhos' na região de Botucatu, SP. Bragantia, Campinas, v. 69, n. 3, p. 571580, 2010.

LOJAN, L. Tendências del crecimiento radial de 23 especies forestales del trópico. Turrialba, San José, v. 18, n. 3, p. 275-281, 1968.

MERCANTE, F. N. et al. Biomassa microbiana, em um Argissolo Vermelho, em diferentes coberturas vegetais, em área cultivada com mandioca. Acta Scientiarum Agronomy, Maringá, v. 34, n. 4, p. 479-485, 2008.

MERRIAN, J. L.; KELLER, J. Farm irrigation system evaluation: a guide for management. Logan: Utah State University, 1978.

NEVES, C. S. V. J.; FELLER, C.; KOUAKOUA, E. Efeito do manejo do solo e da matéria orgânica solúvel em água quente na estabilidade de agregados de um Latossolo argiloso. Ciência Rural, Santa Maria, v. 36, n. 5, p. 14101415, 2006.

NICOTRA, A. B.; DAVIDSON, A. Adaptive phenotypic plasticity and plant water use. Functional Plant Biology, Victoria, v. 37, n. 1, p. 117-127, 2010.

NORBERTO, P. M.; CHAFUN, N. N. J.; PASCAL, M. Efeitos da época de poda, cianamida hidrogenada e irrigação na produção de figos verdes. Pesquisa Agropecuária Brasileira, Brasília, DF, v. 36, n. 11, p. 13631369, 2001.
PENTEADO, S. R.; FRANCO, J. A. M. Figo (Ficus carica L.). In: MANUAL técnico das culturas. Campinas: SAA/ CATI/DCT, 1997. p. 127-139.

POORTER, H.; NAGEL, O. The role of biomass allocation in the growth response of plants to different levels of light, $\mathrm{CO}_{2}$, nutrients and water: a quantitative review. Australian Journal of Plant Physiology, Collingwood, v. 27, n. 4, p. 595-607, 2000.

REICHARDT, K.; TIMM, L. C. Solo, planta e atmosfera: conceitos, processos e aplicações. Barueri: Manole, 2004.

REIS, G. N. et al. Manejo do consórcio com culturas de adubação verde em sistema de plantio direto. Acta Scientiarum Agronomy, Maringá, v. 29, n. 5, p. 677-681, 2007.

RESENDE, F. V. et al. Uso de cobertura morta vegetal no controle da umidade e temperatura do solo, na incidência de plantas invasoras e na produção da cenoura em cultivo de verão. Ciência e Agrotecnologia, Lavras, v. 29, n. 1, p. 100-105, 2005.

RODRIGUES, M. G. F.; CORRÊA, L. S.; BOLIANI, A. C. Avaliação de seleções mutantes de figueira cv. Roxo-deValinhos. Revista Brasileira de Fruticultura, Jaboticabal, v. 31, n. 3, p. 771-777, 2009.

ROSA, M. E. C.; NAVES, R. V.; OLIVEIRA JÚNIOR, J. P. Produção e crescimento de mudas de mangabeira (Hancornia Speciosa Gomez) em diferentes substratos. Pesquisa Agropecuária Tropical, Goiânia, v. 35, n. 2, p. 65-70, 2005.

RUFATO, L. et al. Coberturas vegetais no desenvolvimento vegetativo de plantas de pessegueiro. Revista Brasileira de Fruticultura, Jaboticabal, v. 29, n. 1, p. 107-109, 2007.

SALMI, G. P.; SALMI, A. P.; ABBOUP, A. C. S. Dinâmica de decomposição e liberação de nutrientes de genótipos de guandu sob cultivos em aleias. Pesquisa Agropecuária Brasileira, Brasília, DF, v. 41, n. 4, p. 676-678, 2006.

SILVA, L. C.; BELTRÃO, N. E. M.; AMORIM NETO, M. S. Análise de crescimento de comunidades vegetais. Campina Grande: Embrapa Algodão, 2000. (Circular técnica, 34).

SOUZA, A. P. et al. Influência da decomposição de diferentes resíduos vegetais submetidos a lâminas de irrigação no comportamento da vegetação espontânea. Acta Scientiarum Agronomy, Maringá, v. 32, n. 2, p. $317-$ 324, 2010.

VAN GENUCHTEN, M. T. A closed-form equation for predicting the conductivity of unsatured soils. Soil Science Society of America Journal, Madison, v. 44, n. 5, p. 892898, 1980.

VIDIGAL, S. M. et al. Produtividade de cebola em cultivo orgânico utilizando composto à base de dejetos de suínos. Horticultura Brasileira, Brasília, DF, v. 28, n. 2, p. 168$173,2010$. 